\title{
Control of anabolic hormone residues in tissues of slaughter animals in Poland during the period of 2011-2015
}

\author{
Iwona Matraszek-Żuchowska, Barbara Woźniak, Alicja Kłopot, \\ Sebastian Witek, Katarzyna Sielska, Andrzej Posyniak \\ Department of Pharmacology and Toxicology, \\ National Veterinary Research Institute, 24-100 Pulawy, Poland \\ iwona.matraszek@ piwet.pulawy.pl
}

Received: September 12, 2016 Accepted: March 13, 2017

\begin{abstract}
Introduction: Studies of anabolic hormone residues in the tissues of slaughter animals have been carried out in Poland for more than 25 years. During the period of 2011 to 2015, a total of 35387 samples from different animal species were tested in the National Residue Control Programme for the presence of residues of compounds that cause hormonal effects, as listed in Annex 1 of Directive 96/23/EC. Material and Methods: The research was conducted in the National Reference Laboratory and eight regional laboratories in departments of veterinary hygiene located throughout the country. Urine, muscle tissue, serum, kidney fat, and drinking water were the targeted matrices. Test methods based on instrumental techniques such as gas and liquid chromatography coupled with mass spectrometry were applied, as well as enzyme-linked immunosorbent assays (ELISA). Results: The concentration of detected hormones exceeded the decision limits in 30 samples, the consequence of which was 41 non-compliances with current applicable criteria. The hormones found present pseudo-endogenous (nortestosterone and boldenone) only, while synthetic hormones were not identified. Conclusion: The non-compliant findings constitute a small percentage $(0.085 \%)$ of the five-year analysis compilation. On this basis the related food produced in Poland can be accepted as safe for human consumption with regard to the hormone residues tested.
\end{abstract}

Keywords: meat-producing animals, anabolic hormones, screening and confirmatory methods, residues, non-compliant results.

\section{Introduction}

The main aim in the production of animals for slaughter is to achieve maximum profits while minimising treatment and costs. For more than 60 years, the use of anabolic hormones in breeding and production of animals for slaughter has brought significant economic benefits to farmers, as it causes faster animal growth in a shorter time $(1,12)$. Anabolic hormones are effectively used in cattle (also in sheep and less commonly in pigs), and in particular in animals with low levels of endogenous sex hormones (calves, heifers, and oxen), to compensate for the shortage of natural hormones. Natural hormones such as oestradiol, testosterone, or progesterone are not very effective when administered orally or parenterally. Thus, for anabolic purposes mainly implants are used in the commercial production of slaughter animals.
Implant compounds are in the form of derivatives, which act longer and more effectively (31). Anabolic hormones cause additional weight gain of $10 \%-30 \%$ and improve feed efficiency by about $10 \%$. Many studies have shown that carcasses from animals treated with anabolic hormones contain less fat, and that the meat is leaner (21). Also, there are no differences between the organoleptic characteristics of meat produced using hormonal growth promoters and meat produced without them.

The action mechanism of hormones in living organisms is relatively simple: they reach the target cells in body fluids (usually via blood). The presence of specific receptors having targeted activity facilitates the selection of appropriate hormones in the cell (28). Hormone receptors are located in the cytoplasm or nucleus of a cell. After the hormone molecule combines with a receptor, the receptor is activated and 
acquires the ability to join deoxyribonucleic acid (DNA) and induce transcription of ribonucleic acid (mRNA). RNA encodes the synthesis of proteins which as enzymes control metabolic processes (34).

On the initiative of the European Commission, a number of studies on the toxicity of particular hormones have been conducted during recent years in order to identify potential risks to consumer health arising from the presence of hormone residues in meat and meat products.

According to the International Agency for Research on Cancer (IARC), diethylstilboestrol and oestrogens are compounds carcinogenic to humans (group 1A), androgenic anabolic steroids are classified as substances probably carcinogenic to humans (group 2A), while gestagens are placed in group 2B designating compounds with possible carcinogenicity to humans (33).

Hormonally active compounds may be present in various biological matrices, such as serum, hair, skin, fat, and plasma. Their origin in samples may be endogenous, their production a part of the species physiology under certain conditions such as pregnancy, stress, or injury, alternatively their production may ensue in the presence of special enzymes or bacteria, or their formation may follow the action of external factors (17). Their presence may also be associated with the treatment of animals via injection, by oral administration, in feed/drinking water, or by implantation (24).

In the European Union (EU) the use of hormones for anabolic purposes is prohibited according to Council Directive 96/22/EC (6); however, in some countries, e.g. Canada, Australia, and the USA, hormones such as oestradiol, testosterone, progesterone, and their esters are authorised and usually administered in the form of implants. The permissibility of hormone residues in animal tissues as a result of implantation is still being debated by breeders and scientists. Proponents of the use of hormones in animal production demonstrate that the administration of hormonal preparations to animals in a controlled manner eliminates the risk of residues in concentrations above a certain safety level. Opponents of the use of hormones in food production claim that there is a threat to the health of the consumer.

Children are particularly vulnerable to the effects of hormones because physiological levels of sex hormones in their bodies are very low compared to the levels in adults. Each additional dose of hormones, even in very small amounts, can have a negative impact on the course of metabolic reactions in the child organism. The sexual organs are also extremely sensitive to even the smallest doses of hormones applied from outside the endocrine system. Therefore, as regard for consumer welfare demands, the use of hormonal growth promoters in production of animals for slaughter has been prohibited in the EU since 1988.
In practice, the prohibition of the use of anabolic compounds means that they should not be present in biological samples from animals intended for human consumption. Accordingly, there are no maximum residue levels (MRLs) established for banned compounds. However, the situation is more complicated with respect to natural hormones. In addition, some steroid hormones such as nortestosterone and boldenone can occur endogenously in selected species, but the criteria for the interpretation of the results in such cases have not been clearly defined. Based on the available data concerning the natural hormone levels in serum, reference values have been established for $17 \beta$-oestradiol and testosterone depending on the age and sex of the animals. In order to standardise control rules in the EU member states, where analytical methods have been used in research laboratories with different performance standards, minimum required performance limits (MRPLs) have been established in accordance with Commission Decision 2002/657/EC (5). Formally, in the hormones group, an MRPL value only exists for medroxyprogesterone acetate in kidney fat, and is presently established at $1 \mu \mathrm{g} \mathrm{kg}^{-1}$. The European Union Reference Laboratories (EURLs) have submitted a technical guideline in order to improve and harmonise result interpretation for substances without MRLs, using analytical methods for residue control. Following this guideline, Recommended Concentration (RC) values have been proposed for control purposes for the other anabolic hormones (9). Nevertheless, they are dependent on the matrix tested and do not have legal force.

Since 1990 research on hormone residues in tissues and body fluids of slaughter animals has been conducted in Poland under the official veterinary system. Consequent to Council Directive 96/23/EC of 29 April 1996, the Polish Chief Veterinary Officer and the European Commission approved the National Residue Control Programme to implement the Directive, and subsequently hormone residue research has also come into the ambit of this programme. The Polish National Residue Control Programme is fully conformant to international requirements, and its study principles are consistent with the recommendations of the Directive and the Polish Regulation of the Minister of Agriculture and Rural Development of 29 August 2006. These documents also define the scope of research and sampling strategy carried out under the programme $(7,25)$.

The number of animals to be inspected for hormone residues each year depends strictly on the number of animals slaughtered in the country in the previous year. The presence of anabolic steroids is tested in the tissues of listed species of slaughter animals such as cattle, pigs, sheep, goats, horses, poultry (chickens, turkey, geese, and ducks), rabbit, fish, and farmed game. 
In Poland, testing has been and continues to be conducted for 23 recommended compounds and their metabolites from the following groups:

1 - stilbenes (A1): diethylstilboestrol (DES), dienoestrol (DIE), and hexoestrol (HEX);

2 - steroids (A3): 19-nortestosterone (19-NT) (17 $\alpha / \beta$-forms), boldenone (BOL) (17 $\alpha / \beta$-forms), methylboldenone (MBOL), methyltestosterone (MT), trenbolone $(\mathrm{TBOH})(17 \alpha / \beta$-forms), ethinyloestradiol (EE2), stanozolol (STAN) and 16 $\beta$-OH-stanozolol (16ß-OH-STAN), 17ß-oestradiol (E2), testosterone (T), medroxyprogesterone acetate (MPA), melengestrol acetate (MLGA), megestrol acetate (MGA), and chlormadinone acetate (CMA); and

3 - resorcylic acid lactones (RALs) (A4): zeranol (ZER) and its metabolites taleranol (TAL) and zearalanone (ZAN).

The specific compound selection tested for depends on the animal species and the test material.

The anabolic hormones that are recommended by the EURL - Institute of Food Safety (RIKILT) for testing are all included in the Polish control programme.

The National Residue Control Programme to investigate chemical residues in tissues and food of animal origin is primarily intended to protect consumers against hazardous substances. That testing conducted in the EU be wide, versatile, and according to uniform principles is also one of the basic preconditions of trade. Considering the above, the desirability of these studies is highly justified.

\section{Material and Methods}

Sampling. The research material constituted samples of urine, muscles, serum, kidney fat, and drinking water, which were taken between 2011 and 2015 by authorised veterinary sanitary inspectors throughout Poland. The pool of samples had internal differentiation into three sample kinds according to how they were collected. The first group were targeted samples taken in accordance with the specifications of an authorised National Residue Control Programme for the presence of prohibited substances and chemical and biological residues of medicinal products in live animals and animal products. The second category were suspect samples reported for follow-up, taken as a consequence of non-compliant result found, or samples inviting suspicion of illegal treatment administration. Targeted samples transported from third countries or brought to market in Poland through trade between EU member states and collected in the Polish provinces or at the state border constituted the third sort of samples. The samples for testing were taken from live animals on the farm or in slaughterhouses, in accordance with the requirements of national and EU legislation in terms of the levels of sampling. The range of samples for research spanned cattle, pigs, sheep, goats, horses, poultry (chickens, turkey, geese, and ducks), rabbit, fish, and farmed game. Urine was collected from cattle, pigs, sheep, goats, and horses; muscle tissue was taken from poultry, fish, rabbit, and farmed game; drinking water originated from pig and poultry drinkers on the farm; serum was obtained from cattle, and kidney fat removed from cattle, pigs, sheep, and goats. During the period 2011 to 2015, about 7000 samples were tested per annum for residues of hormones belonging to groups A1, A3, and A4. The number of samples tested for each animal species was based on domestic production indicating the number of animals slaughtered or tonnage of certain goods produced in the previous year. The number of collected samples was consistent with sampling frequency requirements (taking into account the minimum specified by the formula) laid down in Council Directive 96/23/EC and Commission Decision 97/747/EC, while respecting the distribution of samples into sub-groups in group A of the examined compounds $(7,8)$. In the case of banned compounds, during sampling observation criteria such as developed muscle mass, discolouration of muscles, traces of injections in the fatty tissue, traces of implants, presence of swellings, and cysts in post injection sites, as well as the availability of the hormonal preparations on the farm were assessed. Particular attention was also paid to the proper protection of samples after collection, to their labelling, and to the preparation of relevant documentation containing information on the gender and age of the animals and maintenance of suitable storage conditions of samples prior to delivery to the laboratory. In Poland, testing for anabolic hormones is conducted at the National Reference Laboratory in Pulawy and five regional laboratories located in Bialystok, Gdansk, Katowice, Poznan, and Warsaw. Official inspectors from the Veterinary Sanitary Inspection Service have the responsibility for sending collected samples to designated laboratories according to a schedule. During the five years (2011-2015), a total of 35,387 samples from all species of animals covered in the plan were collected.

Parallel to the official examination of hormone residues carried out under the Polish National Residue Control Programme, diagnostic analysis of commercial samples at the request of individual clients was also conducted. In the National Reference Laboratory in Pulawy, Poland, in the same five-year period, 208 different commercial samples including 146 samples of muscle tissue, 41 samples of raw or powdered milk, and 21 samples of liquid or powdered eggs were tested for the presence of hormone residues and integrated into the study.

Methods. The collected samples were analysed according to the classic model of measurement consisting of two stages. In the first stage the samples were subjected to a study by screening procedures focusing on the selection of suspect samples, simultaneously avoiding false negative results. In cases 
where the concentration of the tested analyte exceeded the detection capability value (CC $\beta)$, the samples were sent to the National Reference Laboratory in Pulawy in order for the second stage confirmatory analysis to be performed focusing on the unambiguous identification of the analyte. When the concentration of the analyte in a sample analysed by a confirmatory method exceeded the decision limit value $(\mathrm{CC} \alpha)$, the sample was classified as non-compliant with the applicable criteria. The screening methods used in the research were based mainly on gas chromatography and liquid chromatography with mass spectrometry, although some laboratories also applied the enzyme-linked immunosorbent assay (ELISA) method. In accordance with the requirements of Commission Decision 2002/657/EC, for confirmation use was made only of methods based on gas/liquid chromatography with spectrometric detection which did not deviate from the specified outlines including the criteria for identification. All analytical procedures used in the studies concomitant with official monitoring of hormones in Poland were validated in accordance with Commission Decision 2002/657/EC rules and accredited. The methods used in inspection studies met the required criteria concerning the validation of performance and allowed determination of various hormones in different biological matrices of animal origin at concentrations well below the recommended concentrations (RC). The methods used for confirmation have been verified with a positive result in proficiency testing organised by RIKILT in the Netherlands and other European institutions authorised to carry out such tests as Progetto Trieste or FAPAS (Food Analysis Performance Assessment Schemes).

\section{Results}

In Poland between 2011 and 2015, 35,387 samples taken throughout the country were examined for the presence of hormone residues. A summary of the results of the control studies of hormone residues in Poland is presented in Table 1. As shown in the table, 4741 samples were tested for the presence of residues of stilbenes from group A1 in accordance with the classification in Directive 96/23/EC. Most of the samples, $(26,009)$, were examined for the residues of steroid hormones from group A3. In total, 4637 samples of compounds from the group A4 of resorcylic acid lactones were also checked. The largest number of samples $(35,270)$, being more than $99.6 \%$ of the tested total, were targeted samples collected in accordance with the National Residue Control Programme. Only a relatively small number of test specimens were suspect samples (50) or targeted samples imported into the country (67), which are minor percentages (less than $0.2 \%$ ), namely $0.14 \%$ and $0.19 \%$ of the total number of samples, respectively. Most of the entire pool of samples that were examined were collected from cattle and pigs (more than 10,000 samples for each species). Slightly fewer were collected from chickens, many fewer from turkey, and from 30 to 500 times fewer samples from other species reached the study than those from cattle and pigs. During 2011 to 2015, 18,033 urine samples (the largest amount being from cattle), 8905 muscle samples (the largest amount being from poultry), 2400 kidney fat samples, 3555 serum samples, and 2494 samples of drinking water were examined for the presence of anabolic hormone residues.

In summary, the results over the five-year study show that only 41 non-compliant results were reported ( 1 in cattle urine, 3 in horse urine, and 37 in pig urine).

In the A1 group of compounds there were no positive results identified in any tested biological matrices originating from animal species covered by the programme. All the aforementioned 41 positive results were found in the A3 group, among the steroid compounds. Of these, high residue cases related to the presence of 19-nortestosterone reached 27, divided between the $17 \beta$-form of 19 -nortestosterone ( 24 cases) and the $17 \alpha$-form ( 3 cases), while the remaining 14 cases referred to the presence of residues of boldenone, 8 cases presenting the $17 \beta$-form of boldenone and 6 the $17 \alpha$-form.

A detailed summary of the samples submitted to the National Reference Laboratory in Pulawy for confirmatory analysis as well as non-compliant results identified each year is presented in Table 2.

The 19-nortestosterone was detected in urine samples taken from cattle, pigs and horses. A single high-residue result was identified in the urine of cattle, in which $1.6 \mu \mathrm{g} \mathrm{L}^{-1} \pm 0.7 \mu \mathrm{g} \mathrm{L}^{-1}$ of $17 \alpha-19$-nortestosterone was found. The largest number of results (23 cases) with excessive 19-nortestosterone (17 $\beta$-form) residues was reported in the urine of pigs, in which a large variation of analyte concentrations was observed. Three noncompliant results came from pigs urine, where the concentration of 17 $\beta$-19-nortestosterone was close to the

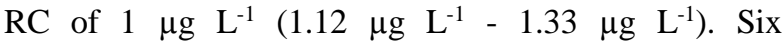
subsequent non-compliant-results were yielded by pig urine samples in which the concentration of 17 $\beta-19$ nortestosterone exceeded the RC of $1 \mu \mathrm{g} \mathrm{L}^{-1}$, but did not exceed $10 \mu \mathrm{g} \mathrm{L}^{-1}$ and was in the range from $1.7 \mu \mathrm{g} \mathrm{L}^{-1}$ to $8.5 \mu \mathrm{g} \mathrm{L}^{-1}$. Another single case of a non-compliant finding concerned a urine sample where the concentration of 17 $\beta$-19-nortestosterone exceeded $10 \mu \mathrm{g} \mathrm{L}^{-1}$ and amounted to $12.6 \mu \mathrm{g} \mathrm{L}^{-1}$. In turn, six pig urine non-compliances were detected with the range of $17 \beta-19$-nortestosterone concentration from $20 \mu \mathrm{g} \mathrm{L}^{-1}$ to $50 \mu \mathrm{g} \mathrm{L}^{-1}$ : the lowest concentration was $21.5 \mu \mathrm{g} \mathrm{L}^{-1}$ and the highest was $38.6 \mu \mathrm{g} \mathrm{L}^{-1}$. One raised residue result concerned a case where the 17 $\beta$-19-nortestosterone concentration exceeded $50 \mu \mathrm{g} \mathrm{L} \mathrm{L}^{-1}$ and reached $69.1 \mu \mathrm{g} \mathrm{L}^{-1}$. The other six non-compliant results referred to samples in which the concentration of 17ß-19nortestosterone exceeded $100 \mu \mathrm{g} \mathrm{L}^{-1}$ and ranged from $131.3 \mu \mathrm{g} \mathrm{L}^{-1}$ to $514.7 \mu \mathrm{g} \mathrm{L}^{-1}$. 
Table 1. The results of examination of anabolic hormone residues in biological material of animal origin in Poland in 2011-2015

\begin{tabular}{|c|c|c|c|c|c|c|c|c|c|c|c|c|c|c|c|}
\hline \multirow[b]{2}{*}{ 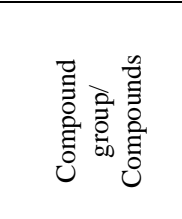 } & \multicolumn{15}{|c|}{ The number of samples tested } \\
\hline & 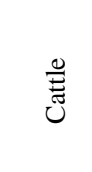 & $\mathscr{0}$ & 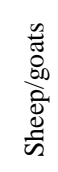 & 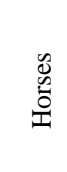 & 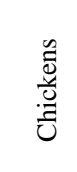 & 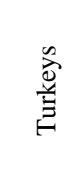 & 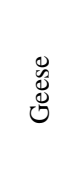 & $\begin{array}{l}\frac{n}{0} \\
\tilde{0}\end{array}$ & $\begin{array}{l}\stackrel{\mathscr{n}}{0} \\
\stackrel{0}{0} \\
\tilde{n}\end{array}$ & $\begin{array}{l}\frac{1}{5} \\
\text { 诖 } \\
\end{array}$ & 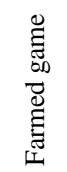 & 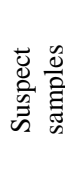 & $\begin{array}{l}\stackrel{\overline{0}}{0} \\
\stackrel{0}{\Xi}\end{array}$ & 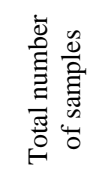 & 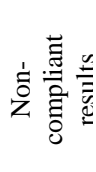 \\
\hline \multicolumn{16}{|c|}{ Group A1 } \\
\hline Stilbenes $^{1}$ & 1013 & 1312 & 5 & 26 & 1835 & 254 & 72 & 156 & 7 & 32 & 5 & & 24 & 4741 & \\
\hline \multicolumn{16}{|c|}{ Group A3 } \\
\hline $19 \mathrm{NT}^{1}$ & 778 & 3698 & 5 & 25 & 1725 & 237 & 60 & 44 & 9 & 67 & 5 & 36 & 22 & 6711 & 27 \\
\hline $\mathrm{TBOH}^{1}$ & 721 & 1429 & 5 & 22 & 1759 & 237 & 67 & 46 & 8 & 64 & 4 & & 7 & 4369 & \\
\hline $\mathrm{MT}^{1}$ & 718 & 1452 & 5 & 20 & 1762 & 227 & 59 & 33 & 5 & 64 & 4 & & 5 & 4354 & \\
\hline $\mathrm{EE} 2^{2}$ & 705 & 1386 & 5 & 20 & & & & & & & & & & 2116 & \\
\hline $\mathrm{BOL}, \mathrm{MeBOL}^{3}$ & 1532 & 203 & & & & & & & & & & 14 & & 1749 & $\begin{array}{c}14 \\
(\mathrm{BOL})\end{array}$ \\
\hline STAN $^{3}$ & 755 & & & & & & & & & & & & & 755 & \\
\hline $\mathrm{E} 2^{4}$ & 1777 & & & & & & & & & & & & & 1777 & \\
\hline $\mathrm{T}^{4}$ & 1778 & & & & & & & & & & & & & 1778 & \\
\hline Gestagens ${ }^{5}$ : & & & & & & & & & & & & & & & \\
\hline $\begin{array}{l}\text { MPA, MGA } \\
\text { CMA, MLGA }\end{array}$ & 805 & 1579 & 10 & & & & & & & & & & 6 & 2400 & \\
\hline \multicolumn{16}{|c|}{ Group A4 } \\
\hline $\begin{array}{l}\text { Resorcylic } \\
\text { acid lactones }{ }^{1} \text { : } \\
\text { ZER, TAL, } \\
\text { ZAN }\end{array}$ & 1003 & 1477 & 5 & 25 & 1782 & 225 & 66 & 41 & 5 & 1 & 4 & & 3 & 4637 & \\
\hline \multicolumn{16}{|c|}{ Summary } \\
\hline $\begin{array}{l}\text { Total number } \\
\text { of samples }\end{array}$ & 11585 & 12536 & 40 & 138 & 8863 & 1180 & 324 & 320 & 34 & 228 & 22 & 50 & 67 & 35387 & \\
\hline $\begin{array}{l}\text { Non-compliant } \\
\text { results }\end{array}$ & 1 & 37 & & 3 & & & & & & & & & & & 41 \\
\hline
\end{tabular}

Table 2. Summary of the confirmatory study in the National Reference Laboratory in 2011-2015

\begin{tabular}{|c|c|c|c|c|c|c|}
\hline \multirow{2}{*}{ Compound } & \multicolumn{5}{|c|}{ The number and origin of samples directed to confirmatory study } & \multirow[b]{2}{*}{$2011--2015$} \\
\hline & 2011 & 2012 & 2013 & 2014 & 2015 & \\
\hline Stilbenes & $5(b-4, p-1)$ & $1(b)$ & $2(p)$ & - & $2(b-1, w-1)$ & 10 \\
\hline $19-\mathrm{NT}$ & $7(b-2, p-5)$ & $9(p)$ & $6(b-1, p-4, h-1)$ & $8(p)$ & $8(b-4, p-4)$ & 38 \\
\hline $\mathrm{TBOH}$ & $1 *(c h)$ & $5(p)$ & $1(p)$ & $1(p)$ & - & 8 \\
\hline MT & $4(b-1, p-3)$ & $9(b-2, p-7)$ & $1(p)$ & $7(b-1, p-6)$ & - & 21 \\
\hline EE2 & $1(p)$ & - & - & - & - & 1 \\
\hline BOL, MeBOL & $4(b-2, p-2)$ & $3(b-1, p-2)$ & $1(p)$ & $6(b-1, p-5)$ & $4(b-2, p-2)$ & 18 \\
\hline STAN & - & - & - & - & - & - \\
\hline E2 & - & - & - & $2 * * *(b)$ & - & 2 \\
\hline $\mathrm{T}$ & - & - & - & - & - & - \\
\hline Gestagens & - & $1 * *(p)$ & - & - & - & 1 \\
\hline $\begin{array}{l}\text { Resorcylic acid } \\
\text { lactones }\end{array}$ & - & $1 *(c h)$ & $1(p)$ & $2(b)$ & $3(b-2, p-1)$ & 7 \\
\hline $\begin{array}{l}\text { Total number of } \\
\text { samples taken }\end{array}$ & 6845 & 6830 & 7028 & 7187 & 7497 & 35387 \\
\hline $\begin{array}{l}\text { Total number of } \\
\text { samples confirmed }\end{array}$ & 22 & 29 & 12 & 26 & 17 & 106 \\
\hline $\begin{array}{l}\text { Non-compliant } \\
\text { samples }\end{array}$ & 4 & 7 & 5 & 8 & 6 & 30 \\
\hline $\begin{array}{l}\text { Percentage of non- } \\
\text { compliant samples } \\
(\%) \text { (in terms of the } \\
\text { number of samples } \\
\text { confirmed) }\end{array}$ & 18.2 & 24.1 & 41.7 & 30.8 & 35.3 & 28.3 \\
\hline $\begin{array}{l}\text { Percentage of non- } \\
\text { compliant samples } \\
(\%) \text { (in terms of the } \\
\text { total number of } \\
\text { samples taken) }\end{array}$ & 0.058 & 0.102 & 0.071 & 0.223 & 0.080 & 0.085 \\
\hline $\begin{array}{l}\text { Non-compliant } \\
\text { results }\end{array}$ & $5(p)$ & $7(p)$ & $7(p-5, h-2)$ & $16(p)$ & $6(b-1, p-4, h-1)$ & 41 \\
\hline
\end{tabular}

$*$ - muscle sample, $* *$ - kidney fat sample, $* * *$ - serum sample

$b$-cattle, $p$-- pigs, $h$ - horses, $c h$ - chickens, $w$ - water 
The presence of 19-nortestosterone residues was also observed in horse urine. One of the three noncompliant results was found in a sample in which the concentration of $17 \alpha-19$-nortestosterone (the main metabolite in cattle) exceeded the RC of $1 \mu \mathrm{g} \mathrm{L}^{-1}$ and amounted to $2.27 \pm 0.68 \mu \mathrm{g} \mathrm{L}^{-1}$. In the second case the concentrations of $17 \alpha / \beta-19$-nortestosterone deviated little from $4 \mu \mathrm{g} \mathrm{L}^{-1}\left(3.7 \mu \mathrm{g} \mathrm{L}^{-1} \pm 1.1 \mu \mathrm{g} \mathrm{L}^{-1}\right.$ of $17 \beta-19$ nortestosterone and $4.3 \mu \mathrm{g} \mathrm{L}^{-1} \pm 1.9 \mu \mathrm{g} \mathrm{L}^{-1}$ of $17 \alpha-19$ nortestosterone).

Representative multiple reaction monitoring (MRM) chromatograms of the urine sample mentioned above from a male horse aged 3.5 years, together with a spiked urine sample (at RC level $1 \mu \mathrm{g} \mathrm{L}^{-1}$ ) analysed in the same test sequence are presented in Fig. 1.

With respect to boldenone, 14 non-compliant results for this compound residue ( $17 \beta$ - and $17 \alpha$-forms) were detected only in urine samples from pigs. The determined concentration of $17 \beta$-boldenone in the urine samples ranged from $2.1 \mu \mathrm{g} \mathrm{L}^{-1}$ to $50 \mu \mathrm{g} \mathrm{L}^{-1}$, while that of the $17 \alpha$-form ranged from $3.1 \mu \mathrm{g} \mathrm{L}^{-1}$ to $6.2 \mu \mathrm{g} \mathrm{L}^{-1}$. In some of the samples in which $17 \beta-$ and/or $17 \alpha$-boldenone were determined, simultaneously a high concentration of $17 \beta-19$-nortestosterone was established.
An example of representative LC-MS/MS chromatograms of a urine sample from a sow at the age of 26 months is presented in Fig. 2. The presence in this sample of $17 \beta-19$-nortestosterone at a concentration of

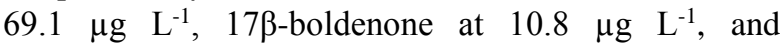
$17 \alpha$-boldenone at $3.9 \mu \mathrm{g} \mathrm{\textrm {L } ^ { - 1 }}$ was confirmed during 2014. The presence of other compounds from the group of steroids (A3) was not detected. No trenbolone, methyltestosterone, ethinyloestradiol, methylboldenone, stanozolol, or gestagens were exposed in any examined biological matrices originating from animals covered by the control programme. In addition, no cases of concentration limits being surpassed by natural hormones from the group A3 - oestradiol and testosterone were reported.

In the A4 group compounds, just as in the compounds of the A1 group, there were no positive results identified in any material or species in the ambit of the control programme. Furthermore, in commercial samples of muscle tissue, milk, and eggs, which were examined in parallel to the official samples, no residues of anabolic hormones above the determined $\mathrm{CC} \alpha$ (muscle or milk) and $\mathrm{RC}$ of $1 \mu \mathrm{g} \mathrm{L}^{-1}\left(\mathrm{~kg}^{-1}\right.$ for eggs) were found. a
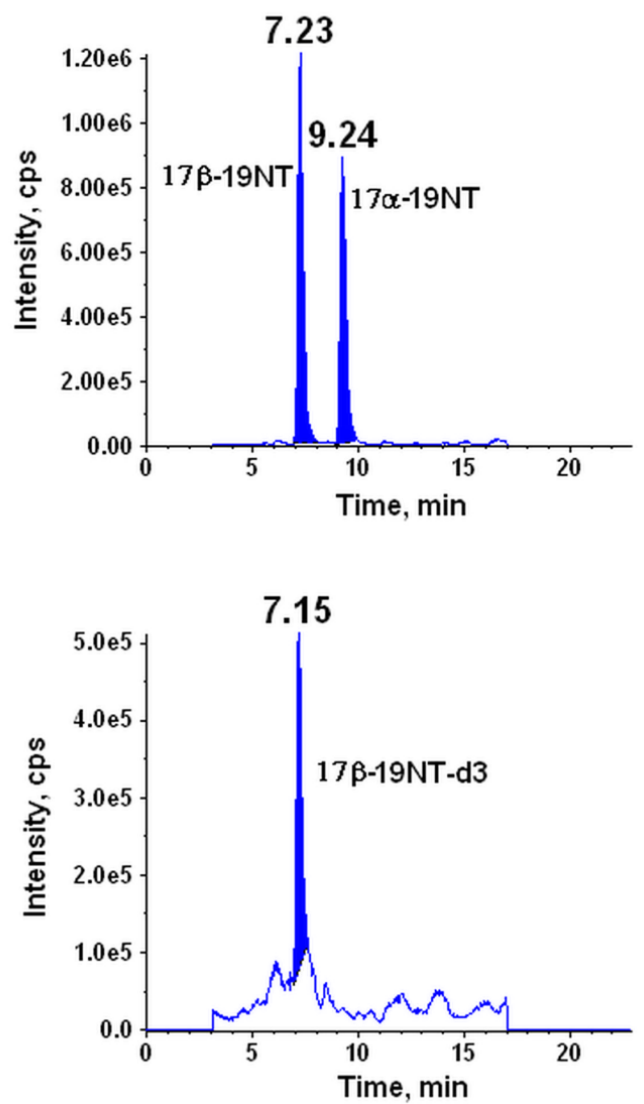

b
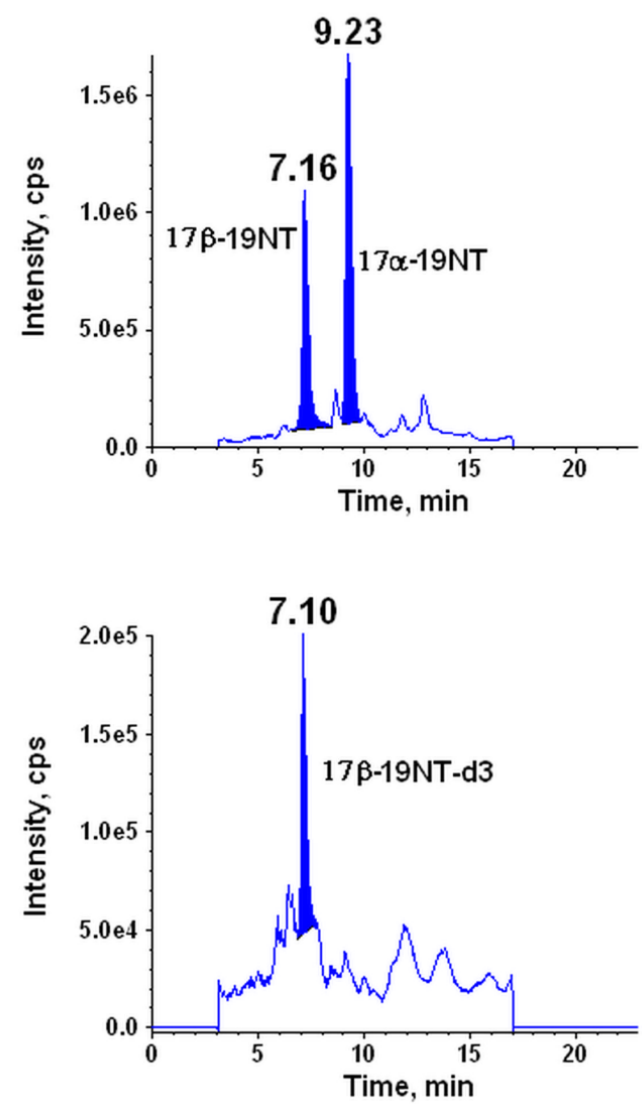

Fig. 1. LC-MS/MS MRM chromatograms of $17 \alpha / \beta-19$-nortestosterone: a) in urine sample spiked at $\mathrm{RC}$ of $1 \mu \mathrm{g} \mathrm{L}^{-1}$ with $17 \beta$ - and $17 \alpha$ - forms; b) in real urine sample from a horse confirmed at $3.7 \mu \mathrm{g} \mathrm{L}^{-1}$ of $17 \beta$-19-nortestosterone and $4.3 \mu \mathrm{g} \mathrm{L}{ }^{-1}$ of $17 \alpha$-19-nortestosterone 
a1
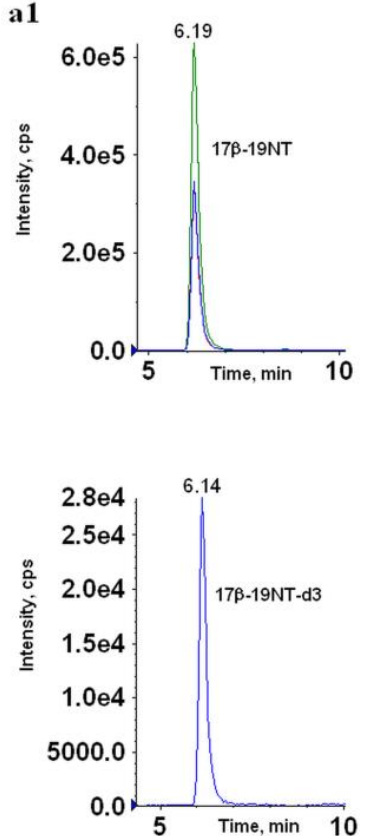

a2
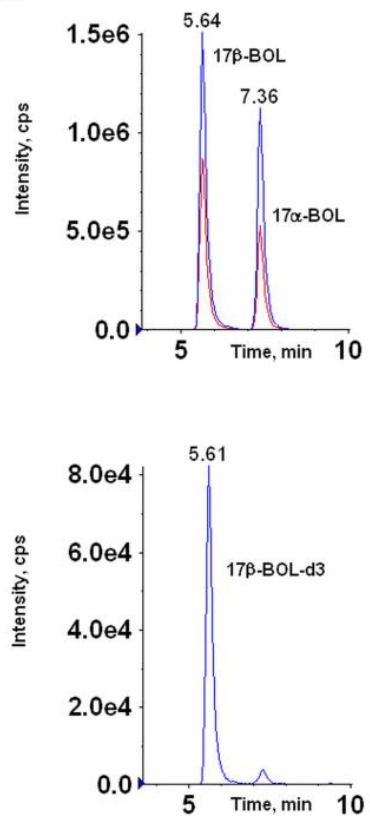

b1
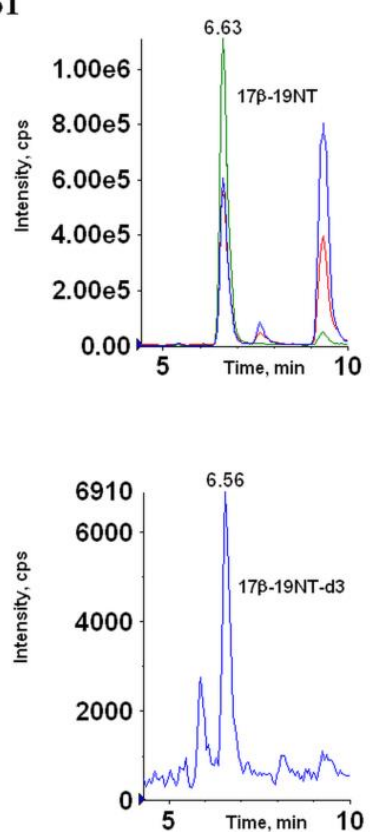

b2
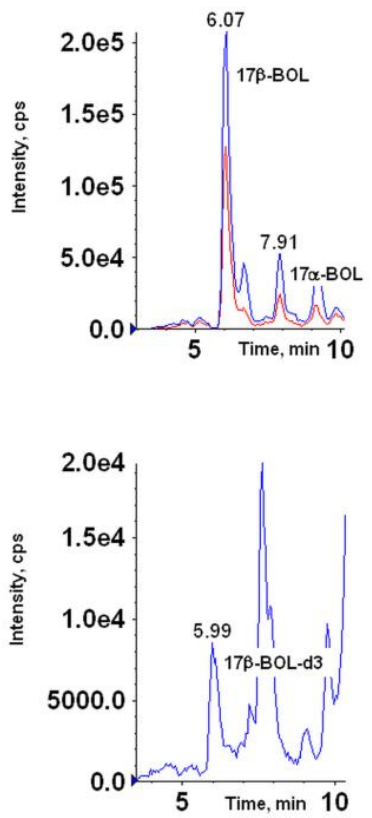

Fig. 2. LC-MS/MS extracted ion chromatograms (XIC) of 17 $\beta$-19-nortestosterone and $17 \alpha / \beta$-boldenone: a1), a2) in urine sample spiked at $10 \mu \mathrm{g} \mathrm{L}^{-1}$; b1), b2) in real urine sample from a pig confirmed at $69.1 \mu \mathrm{g} \mathrm{L}^{-1}$ of $17 \beta$-19-nortestosterone, $10.8 \mu \mathrm{g} \mathrm{L} \mathrm{L}^{-1}$ of $17 \beta$-boldenone, and $3.9 \mu \mathrm{g} \mathrm{L} \mathrm{L}^{-1}$ of $17 \alpha$-boldenone

\section{Discussion}

The effective monitoring of residues of anabolic hormones in slaughter animals provides assurance of the safety of related food for human consumption. In the EU member states, uniform rules for the organisation and performance of official control of food of animal origin are in force. Implementation in the EU member states of the national residue control programmes for the execution of Council Directive 96/23/EC on measures to monitor certain substances and residues thereof in live animals and animal products is important because it enables the elimination of food of insufficient quality and thereby supports the protection of public health.

Conducting laboratory inspections under the auspices of the programme is a requirement of free trade between member states in the EU. Exceptionally, in relation to hormones, monitoring tests are aimed at detecting the use of prohibited substances and identifying the cases of excessive residues in order to allow no detriment to public health. In addition, individual producers of food of animal origin must follow guidelines, general rules of nutritional law, those provisions that are necessary to guarantee the safety of food, and special hygiene requirements in order to protect the life and health of consumers.

In Poland, the legal basis for the control of residues in food of animal origin is the Regulation of the Minister of Agriculture and Rural Development dated 29 August 2006 (25). The Ministry, together with the Veterinary Inspectorate, is responsible for the implementation and execution of the testing programme for residues control. According to the law, each EU member state should designate a National Reference Laboratory responsible for coordinating and overseeing the work of other laboratories in the country engaged in residues analysis. Since the beginning of the research, the role of the coordinator in Poland has been filled by the National Veterinary Research Institute located in Pulawy.

The National Residue Control Plan is constructed each year, taking into account the number of animals slaughtered in the previous year and also considering the results non-compliant with applicable regulations. The principle is to systematically increase the number of samples to be taken for the compounds that have been previously identified in slaughter animal samples. For those compounds/groups of compounds for which there are no non-compliant results, the number of samples scheduled for testing remains unchanged compared to the previous year or is appropriately reduced depending on the situation in the country. On the technical side, the regional plenipotentiary for residue monitoring should include an increase in the number of samples in the next year from the specific area of the country where the noncompliant result was found. Additionally, in the case of banned compounds it is particularly important to collect urine samples, blood, and water from drinking troughs at the farm level in order to eliminate the illegal use of hormones during the production period.

During the sampling, particular attention should be paid to large livestock farms, where the probability 
of the use of hormones is much greater. Samples for hormone residue testing should not be collected from dairy cattle or animals originating from breeding flocks, but only from slaughter animals in which the use of hormonal growth promoters is prohibited.

Research under official control was and still is carried out in designated laboratories for these purposes, i.e. the National Regional Laboratories (Departments of Veterinary Hygiene) and the National Reference Laboratory at the National Veterinary Research Institute in Pulawy. In all of these institutions screening tests are performed. According to the current regulations with regard to substances in group A, it is required that all positive findings recorded after routine screening must further be confirmed by an authorised laboratory (National Reference Laboratory) using reference confirmatory methods (7).

As presented in Table 2, the concentration of detected hormones exceeded the limit of detection capability $(\mathrm{CC} \beta)$ in 106 samples including urine taken from cattle, pigs, and horses, chicken muscles, kidney fat from pigs, and bovine serum during the reporting period. On this basis these deviant samples were qualified for confirmatory analysis in the National Reference Laboratory in Pulawy.

The largest number of samples (38 cases) were sent for confirmatory analysis because of the content found in them of 19-nortestosterone residues. There have also been a large number of samples for confirmatory tests for the presence of boldenone and methyltestosterone residues. In addition, the National Reference Laboratory in Pulawy disproved the presence of residues of stilbenes, trenbolone, ethinyloestradiol, oestradiol, gestagens, and resorcylic acid lactones detected in initial screening. All samples that were sent for confirmatory studies were analysed using validated and accredited confirmatory methods.

When the concentrations of the detected compounds exceeded the $\mathrm{CC} \alpha$, the samples were classified as non-compliant with the ruling evaluation criteria. As shown in Table 2, in 30 non-compliant samples, 41 non-compliant results for individual analytes were identified, because in 8 non-compliant samples, more than one analyte (more than one noncompliant result) was found. The percentage of samples confirmed each year ranged from $18.2 \%$ in 2011 to $41.7 \%$ in 2013. On average, banned compounds were identified in $28.3 \%$ of the samples sent for confirmatory tests between 2011 and 2015. It is worth emphasising that the presence of the hormones was confirmed in samples that were tested in a screening by chromatographic methods. Frequently, the presence of hormones was not confirmed in the samples that were tested in screening by ELISA, which is a method that gives a lot of false positive results.

The percentage of non-compliant samples per year out of the total number of samples collected was in the range of $0.058 \%$ in 2011 to $0.223 \%$ in 2014 , and never exceeded $0.25 \%$. It is noteworthy that non-compliant samples constituted only $0.085 \%$ of the total number of samples tested during 2011-2015. The number of noncompliant results observed in these five years remained constant, with the exception of 2014 when it was twice as high as in the other years.

All non-compliant results identified in these years were presences of steroid hormones from the A3 group, specifically 19-nortestosterone and boldenone.

A statement of non-compliant results initiates an investigation aimed at determining the reason for the presence of prohibited compounds in a sample. In Poland, after receiving information about the detection of a prohibited substance, the District Veterinary Officer launches an immediate investigation on the farm and/or in the related establishment. Additional samples, provisionally categorised suspect, of urine, water, and feeding basin contents are collected from a representative group of animals on the farm in question. Throughout the investigation suspect animals should be kept on the farm under prohibition of movement and sale until the results of suspect sample investigations are determined. The non-compliant results obtained during 2011-2015 and subsequently investigated on the farms of origin attached to no signs or evidence of illegal use of hormones. Also, a review of veterinary and zootechnical documentation did not reveal any irregularities.

Further testing of suspect samples taken from cattle, pigs, and horses during the investigation, failed to confirm the presence of hormones. Accordingly, the origin of the hormones identified in the samples classified as non-compliant has not been established.

Because no evidence of illegal use was found, it was supposed that the compounds had an endogenous nature. With respect to 19-nortestosterone, reports on its natural occurrence in biological samples date back to the 1980s. A review of the research literature indicates that the current state of knowledge on the occurrence of endogenous and pseudo-endogenous hormones allows that 17 $\beta$-19-nortestosterone and its metabolites may occur endogenously in various animal species and humans $(3,4,19,30)$. For example, in pigs, a very high concentration of $17 \beta-19$-nortestosterone may occur in uncastrated boars (51-344 $\left.\mu \mathrm{g} \mathrm{L}^{-1}\right)$ and male pigs called cryptorchid animals with the abnormality of one or both testicles being undescended and in the abdominal cavity or inguinal canal. In contrast, lower concentrations can be observed in urine samples from castrated male specimens (barrows) (to $35 \mu \mathrm{g} \mathrm{L}^{-1}$ ) and in female pigs (both gilts and sows) (to $\left.3 \mu \mathrm{g} \mathrm{L}^{-1}\right)(11,23,26)$.

Taking the above into account, it was decided not to collect urine samples from male pigs for the purposes of the study where the focus was residues of $17 \beta-19$-nortestosterone. However, in our study, all urine samples in which the presence of 19-nortestosterone was confirmed came from female animals. Determination of high concentrations of $17 \beta$-19-nortestosterone in female pigs may indicate that the sex of the animal 
from which the sample was taken has been incorrectly noted, that the individual is a cryptorchid animal, or has one of the various defects of the reproductive system defined as the intersex phenomenon. In the literature, there are also reports on the natural occurrence of $17 \beta-19$-nortestosterone in horses (stallions) and $17 \alpha-19$-nortestosterone in pregnant cows and newborn calves $(18,22,27,29,35)$.

As for boldenone, as early as 2002 a group of experts were trying to determine the origin of this compound in biological samples, following earlier reports of positive results. Based on the conducted experiments, it was found that the presence of $17 \alpha$ - and $17 \beta$-boldenone in urine and faeces of cattle may come from sources other than its illegal use. Consequently a specific procedure for interpretation of results for boldenone in cattle has been proposed.

It was suggested that the presence of conjugates of $17 \beta$-boldenone at any level in the urine of veal calves is evidence of illegal treatment, but the presence of $17 \alpha$-boldenone in urine (to $2 \mu \mathrm{g} \mathrm{L}^{-1}$ ) and faeces of bovine animals may come from sources other than its contraventory administration. Findings of boldenone residue must always be defined as either the free or the conjugated form of $17 \beta$-boldenone. When sampling urine for boldenone determination it is recommended to take special care to avoid faecal contamination of the sample (2). In addition, there are also reports that $17 \beta$-boldenone can occur naturally in male pigs and untreated horses $(10,20)$.

Currently available data and research methods are insufficient to enable reliable differentiation of the endogenous compound from the exogenous. In many research centres in Europe, attempts are being made to explain this phenomenon, based on the knowledge of metabolic profiles of hormones in different animal species. Elucidation now appears possible thanks to the capability of new techniques for analysis and the development of metabolomics. The gas chromatography-isotope ratio mass spectrometry (GCIRMS) method, promising for this purpose and based on the principle for determining the isotope ratio of ${ }^{13} \mathrm{C} /{ }^{12} \mathrm{C}$, has so far had limited use, because of the scant availability of equipment and unsuitably high detection limits. In order to determine the origin of the hormone compounds in biological material of animal origin, EURLs recommend determination of markers of metabolites and determination of hormones in the form administered to animals (esters of hormones) as well as data collection from national programmes to identify threshold levels of natural compounds.

The situation regarding the frequency of noncompliant test results observed in Poland is better than on the rest of the continent. In contrast to other European countries, in Poland there were no noncompliant results showing the presence of hormones from stilbene and the resorcylic acid lactones groups. Based on European Food Safety Agency (EFSA) published reports containing monitoring data during the period of 2011 to 2014 in the EU member states, it can be concluded that in the EU countries various hormones from all groups (A1, A3, and A4) were found in samples of animal origin $(13,14,15,16)$. Four non-compliant results were reported for stilbenes and derivatives (the A1 group of compounds): three cases in 2013 (diethylstilboestrol in cattle and hexoestrol in pigs) and one case in 2014 (diethylstilboestrol in pigs). In previous years (2007-2012), there were no cases of non-compliant results for synthetic stilbenes in biological material of animal origin. Preparations containing stilbenes were withdrawn from use in the $1990 \mathrm{~s}$ and should no longer be available on the market. Stilbenes are extremely hazardous as they can stimulate or induce oncogenesis and cancers (32). Identified cases may indicate a disturbing trend from the point of view of effective protection of consumers from harmful residues.

Within the EU, in the group of steroid hormones (A3), a total of 116 non-compliant results were found including 28 results in 2011, 25 in 2012, 31 in 2013, and 32 in 2014. Anabolic hormones from the group of steroid compounds were detected in different species of animals under surveillance; cattle, pigs, sheep, goats, horses, poultry, animals in aquaculture, and farmed game. The most common analytes in biological samples of animal origin were 19-nortestosterone (17 $\alpha$ - and $17 \beta$-forms) and boldenone (also in two isomeric forms). In individual cases of non-compliant samples, the presence of natural hormones such as testosterone and oestradiol, as well as methyltestosterone, trenbolone, and stanozolol was reported. For the A3 group compounds there were also non-compliant results reported among suspect samples (a total of 18 results in cattle and pigs) and in samples collected for other programmes developed under the national legislation of EU member states (four noncompliant results in cattle). Referring to the resorcylic acid lactones including zeranol (A4), 174 results showing high concentration were reported. There was observation of 19 non-compliant results in 2011, 16 in 2012, 31 in 2013, and 108 in 2014. Compounds from the A4 group (173 results for ZER and TAL together and 1 result for ZAN) were detected in cattle, pigs, sheep, goats, horses, and poultry. In addition, 8 cases of non-compliant results among suspect samples from cattle in 2013 and 2 samples from cattle in 2014 were demonstrated. Although in Poland, the residues of ZER and/or its metabolites (TAL and ZAN) were found in samples during screening tests, following confirmatory studies such samples were considered compliant. The confirmatory method applied in the National Reference Laboratory in Pulawy allows for determination of the RALs profile, i.e. ZER and its metabolites, as well as the mycotoxin-zearalenone ( $\mathrm{ZON})$ and its metabolites: $\alpha$-zearalenol $(\alpha-Z O L)$ and $\beta$-zearalenol ( $\beta$-ZOL). According to the current state of knowledge and recommendations of the EURL in RIKILT in the Netherlands on the matter of hormones, in order to 
correctly interpret the results for the residues of ZER, the metabolic profile of the RALs should be investigated. The determined concentrations of ZER and TAL in many cases may indicate a contamination of the sample with ZON. The final assessment of the result and the discrimination between natural contamination and abuse should be made on the basis of a ratio criterion: that of the concentration of ZER and TAL to that of the sum of the concentrations of mycotoxin ZON and its metabolites $\alpha$-ZOL and $\beta$-ZOL. A resulting ratio of less than 1 indicates that the presence of ZER and other compounds from RALs is due to mycotoxin contamination. Otherwise, when the calculated ratio is significantly higher than 1 , the presence of ZER may be a symptom of illegal use.

The results of monitoring studies conducted in Poland evidences refrainment from the use of anabolic hormones in animal breeding in Poland. On this basis, it can be stated with certainty that food of animal origin produced in Poland is safe for human consumption and free from any of the tested hormonal growth promoters.

Conflict of Interests Statement: The authors declare that there is no conflict of interests regarding the publication of this article.

Financial Disclosure Statement: The investigation was supported by the Polish Ministry of Agriculture and Rural Development under the auspices of the Multiannual Programme "Control of the presence of prohibited substances in food of animal origin and undesirable substances in animal feed".

\section{Animal Rights Statement: None required.}

\section{References}

1. Aitken J.N., Crichton J.A.: The effect of hexestrol implantation on growth and certain carcass characteristics of fattening steers. Br J Nutr 1956, 10, 220-225.

2. Arioli F., Gavinelli M.P., Fracchiolla M.L., Casati A., Fidani M., Ferrer E., Pompa G.: Evaluation of boldenone formation and related steroids transformations in veal faeces by liquid chromatography/tandem mass spectrometry. Rapid Commun Mass Spectrom 2008, 22, 217-223.

3. Buiarelli F., Giannetti L., Jasionowska R., Cruciani C., Neri B.: Determination of nandrolone metabolites in human urine: comparison between liquid chromatography/tandem mass spectrometry and gas chromatography/mass spectrometry. Rapid Commun Mass Spectrom 2010, 24, 1881-1894.

4. Clouet A-S., Le Bizec B., Montrade M-P., Monteau F., Andre F.: Identification of endogenous 19-nortestosterone in pregnant ewes by gas-chromatography-mass spectrometry. Analyst 1997, $122,471-474$

5. Commission Decision No. 2002/657/EC of 12 August 2002 implementing Council Directive 96/23/EC concerning the performance of analytical methods and the interpretations of results. Off J Eur Commun L221, 8-36.

6. Council Directive 96/22/EC of 29 April 1996, concerning the prohibition on the use in stockfarming of certain substances having a hormonal or thyreostatic action and of $\beta$-agonists, and repealing Directives 81/602/EEC, 88/146/EEC and 88/299/EEC. Off J Eur Commun L125:0003-0009.
7. Council Directive 96/23/EC of 29 April 1996, on measures to monitor certain substances and residues thereof in live animals and animal products and repealing Directives 85/358/EEC and 86/469/EEC and Decisions 89/187/EEC and 91/664/EEC. Off J Eur Commun L125:0010-0032.

8. Council Directive 2003/74/EC of 22 September 2003 amending Council Directive 96/22/EC concerning the prohibition on the use in stockfarming of certain substances having hormonal or thyreostatic action and of beta agonists. Off $\mathbf{J}$ Eur Commun L262, 17-21.

9. CRL Guidance Paper of 7 December 2007. CRLs view on state of the art analytical methods for National Residue Control Plans. http://www.rivm.nl/bibliotheek/digitaaldepot/crlguidance2007.pdf.

10. De Brabander H., Poelmans S., Schilt R., Stephany R.W., Le Bizec B., Draisci R., Sterk S.S., van Ginkel L.A., Courtheyn D., Van Hoof N., Macri A., De Wasch K.: Presence and metabolism of the anabolic steroid boldenone in various animal species: a review. Food Addit Contam 2004, 21, 515-525.

11. Debruyckere G., Van Peteghem C.: Detection of 19nortestosterone and its urinary metabolites in miniature pigs by gas chromatography-mass spectrometry. J Chromatogr B 1991, 564, 393-403.

12. Donovan G.A., Sherman W.C.: Analysis of the growth pattern and the body composition of chickens implanted with diethylstilbestrol. Poult Sci 1960, 39, 757-765.

13. EFSA (European Food Safety Authority), 2013. Report for 2011 on the results from the monitoring of veterinary medicinal product residues and other substances in live animals and animal products. EFSA supporting publication 2013:EN-363. 65 pp. Available online: http://www.efsa.europa.eu/publications.

14. EFSA (European Food Safety Authority), 2014. Report for 2012 on the results from the monitoring of veterinary medicinal product residues and other substances in live animals and animal products. EFSA supporting publication 2014:EN-540. 65 pp. Available online: http://www.efsa.europa.eu/publications.

15. EFSA (European Food Safety Authority), 2015. Report for 2013 on the results from the monitoring of veterinary medicinal product residues and other substances in live animals and animal products. EFSA supporting publication 2015:EN-723, 69 pp. Available online: http://www.efsa.europa.eu/publications.

16. EFSA (European Food Safety Authority), 2016. Report for 2014 on the results from the monitoring of veterinary medicinal product residues and other substances in live animals and animal products. EFSA Supporting publication 2016:EN-923. 70 pp. Available online: http://www.efsa.europa.eu/publications.

17. EURL reflection paper: Natural growth promoting substances in biological samples, edited by RIKILT Wageningen UR, Wageningen, 2014.

18. Grace P.B., Drake E.C., Teale P., Houghton E.: Quantification of 19-nortestosterone sulphate and boldenone sulphate in urine from male horses using liquid chromatography/tandem mass spectrometry. Rapid Commun Mass Spectrom 2008, 22, 2999-3007.

19. Hemmersbach P., Große J.: Nandrolone: A multi-Faceted Doping Agent. In: Doping in sports, Handbook of Experimental Pharmacology 195, edited by Thieme D., Hemmersbach P., Springer-Verlag, Berlin Heidelberg, 2010, pp. 127-154.

20. Ho E.N.M., Yiu K.C.H., Tang F.P.W., Dehennin L., Plou P., Bonnaire Y., Wan T.S.M.: Detection of endogenous boldenone in the entire male horse. J Chromatogr B 2004, 808, 287-294.

21. Johnson B.J., Ribeiro F.R.B., Beckett J.L.: Application of growth technologies in enhancing food security and sustainability. Anim Front 2013, 3, 8-13.

22. Kaabia Z., Dervilly-Pinel G., Popot M.A., Baily-Chouriberry L., Plou P., Bonnaire Y., Le Bizec B.: Monitoring the endogeneous steroid profile disruption in urine and blood upon nandrolone administration: An efficient and innovative strategy to screen for nandrolone abuse in entire male horses. Drug Test Anal 2014, 6, 376-388.

23. Poelmans S., De Wasch K., Noppe H., Van Hoof N., Van Cruchten S., Le Bizec B., Deceuninck Y., Sterk S., Van 
Rossum H.J., Hoffman N.K., De Brabander H.F.: Endogenous occurrence of some anabolic steroids in swine matrices. Food Addit Contam 2005, 22, 808-815.

24. Preston R.L.: Hormone containing growth promoting implants in farmed livestock. Adv Drug Deliver Rev 1999, 38, 123-138.

25. Regulation of the Polish Minister of Agriculture and Rural Development of 29 August 2006 amending the regulation on methods of proceedings with prohibited substances, chemical, biological remains, medicinal products and radioactive contaminations in animals and products of animal origin (Journal of Laws 2006, No. 155, item 1113).

26. Roig M., Segura J., Ventura R.: Quantitation of 17ß-nandrolone metabolites in boar and horse urine by gas chromatography-mass spectrometry. Anal Chim Acta 2007, 586, 184-195.

27. Samuels T.P., Nedderman A., Seymour M.A., Houghton E.: Study of the metabolism of testosterone, nandrolone and estradiol in cattle. Analyst 1998, 123, 2401-2404.

28. Scarth J., Acre C., Van Ginkel L., Le Bizec B., De Brabander H., Korth W., Points J., Teale P., Kay J.: Presence and metabolism of endogenous androgenic-anabolic steroid hormones in meatproducing animals: a review. Food Addit Contam 2009, 26, 640-671.

29. Soma L.R., Uboh C.E., Guan F., McDonnell S., Pack J.: Pharmacokinetics of boldenone and stanozolol and the results of quantification of anabolic androgenic steroids in race horses and nonrace horses. J Vet Pharmacol Ther 2007, 30, 101-108.

30. Sterk S., Herbold H., Blokland M., Van Rossum H., Van Ginkel L., Stephany R.: Nortestosterone: endogenous in urine of goats, sheep and mares? Analyst 1998, 123, 2633-2636.

31. Stewart L.: Implanting Beef Cattle. The University of Georgia Cooperative Extension: College of Agricultural and Environmental Sciences, College of Family and Consumer Sciences, Bulletin Reviewed March 2013, 1302, 1-8.

32. World Health Organization, International Agency For Research on Cancer, IARC Monographs on the Evaluation of the Carcinogenic Risks to Humans, Overall Evaluation of Carcinogenicity: An Updating of IARC Monographs Volumes 1 to 42, Supplement 7, Lyon, 1987, 1-42, 1-449.

33. World Health Organization, International Agency For Research on Cancer, IARC Monographs on the Evaluation of the Carcinogenic Risks of Chemicals to Humans, Sex hormones (II), Lyon, 1979, 21, 1-563.

34. Woźniak B.: Steroid hormones - properties, application, residues in food of animal origin. Med Weter 2010, 66, 177-181.

35. Yamada M., Kinoshita K., Kurosawa M., Saito K., Nakazawa H.: Analysis of exogenous nandrolone metabolite in horse urine by gas chromatography/combustion/carbon isotope ratio mass spectrometry. J Pharm Biomed Anal 2007, 45, 654-658. 